\title{
Biosensors for the monitoring of harmful algal blooms Daniel $\mathrm{A}$ McPartlin ${ }^{1}$, Jonathan H Loftus ${ }^{1}$, Aoife S Crawley ${ }^{1}$, Joe Silke ${ }^{2}$, Caroline S Murphy ${ }^{1}$ and Richard J O'Kennedy ${ }^{1}$
}

\begin{abstract}
Harmful algal blooms (HABs) are a major global concern due to their propensity to cause environmental damage, healthcare issues and economic losses. In particular, the presence of toxic phytoplankton is a cause for concern. Current HAB monitoring programs often involve laborious laboratory-based analysis at a high cost and with long turnaround times. The latter also hampers the potential to develop accurate and reliable models that can predict $\mathrm{HAB}$ occurrence. However, a promising solution for this issue may be in the form of remotely deployed biosensors, which can rapidly and continuously measure algal and toxin levels at the point-of-need (PON), at a low cost. This review summarises the issues HABs present, how they are difficult to monitor and recently developed biosensors that may improve $\mathrm{HAB}-$ monitoring challenges.
\end{abstract}

\footnotetext{
Addresses

${ }^{1}$ School of Biotechnology, Dublin City University, Dublin 9, Ireland

${ }^{2}$ Marine Institute, Rinville, Oranmore, Co. Galway, Ireland

Corresponding author: O’Kennedy, Richard J (Richard.okennedy@dcu. ie)
}

scallops. Phycotoxins and cyanotoxins are secondary metabolites produced by marine algae and blue-green algae (cyanobacteria), respectively. These algal toxins accumulate to highly significant levels in the digestive tracts and muscles of these shellfish. Subsequent consumption by humans often results in poisoning and severe illnesses. Their presence is responsible for numerous human intoxications yearly [3]. The toxins' associated potencies are intimately linked to their chemical structure and the organs they target. They are known to cause intoxications to humans, birds and farm animals, and impact negatively on tourism.

Global populations are on the increase and so the demand for uncontaminated food sources has never been as urgent. Governments and food safety authorities now recognise the need to regulate and closely monitor toxin contamination in foods for human and animal consumption. The ability to detect, analyse and monitor these harmful algae and their associated toxins at the required limits necessary to meet legislative requirements to avoid consumer harm must be a worldwide priority.

Currently, the monitoring of HABs and their toxins relies on the use of laboratory-based methods. Light Microscopy (LM) is the principle method used for identification and enumeration of HABs species. However, accurate identification of some species can prove extremely difficult. For example, Figures 1 and 2 display data of occurrences of Azadinium/Heterocapsa spp. off the coasts of Cork and Galway, Ireland, respectively [4,5]. These algal genera are grouped together in this manner due to the difficulty in discerning these algae by LM. Therefore, the data shown may at times under- or over-estimate levels of harmful Azadinium spinosum. The use of further confirmatory methods, such as electron microscopy, is often required for further species identification. In regards to the associated algal toxins, the current detection methods involve the use of expensive chromatography-based separation methods coupled to sensitive detectors [6,7]. In addition to these issues, such laboratory-based methods require trained personnel and have an inherently long turnaround time due to sample transport and handling from the sampling site to the laboratory.

Figure 1 displays the occurrences of Azadinium/Heterocapsa spp. from water sample and AZA toxins extracted from shellfish from coast of Co. Cork, Ireland, from 2013 to 2014. The data show a high abundance of AZA bivalve shellfish such as mussels, clams, oysters and 


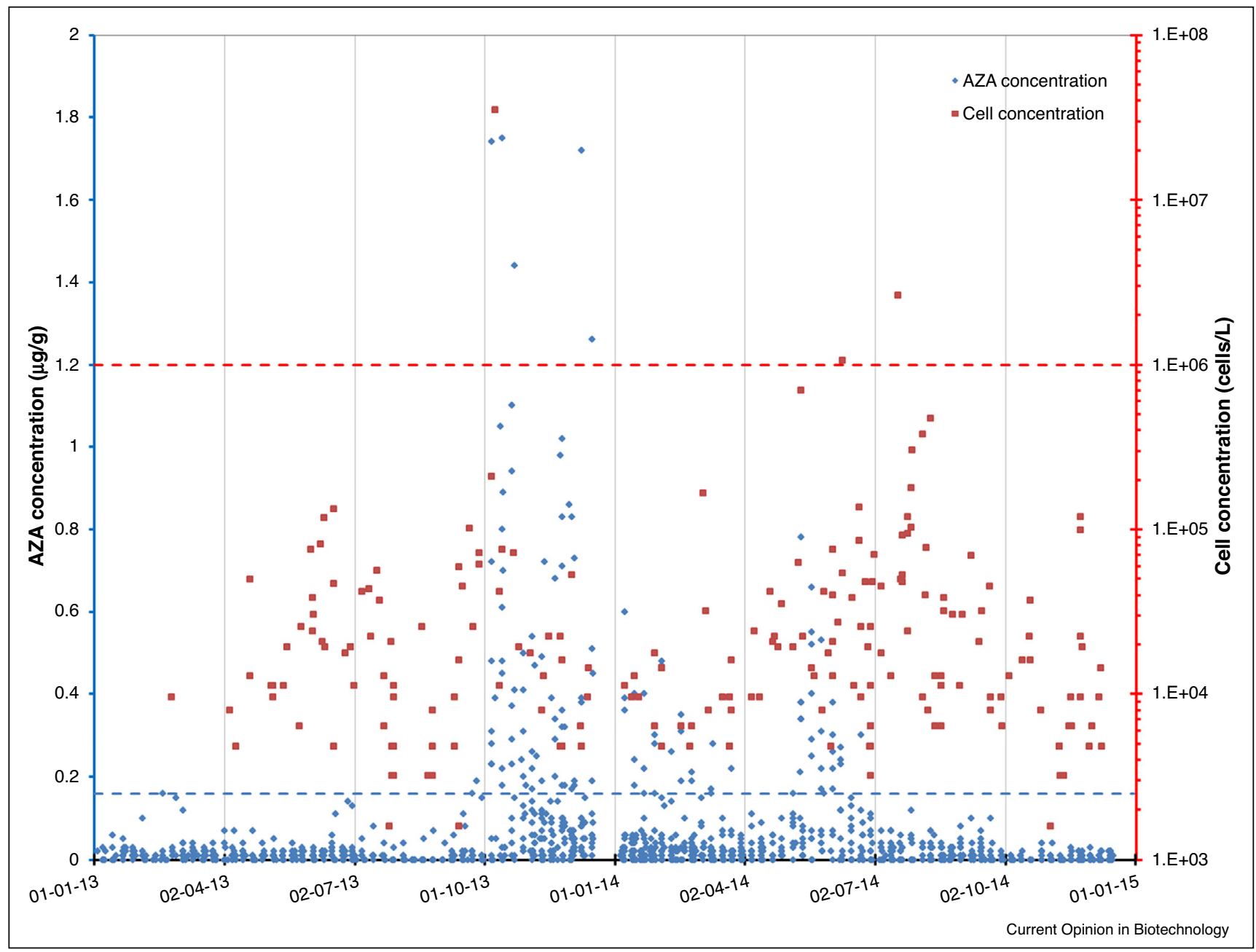

Occurrences of Axadinium/Heterocapsa spp. and AZA toxins (in shellfish) off the Cork coast from 2013 to 2014. Blue dashed line represents the current regulatory cut-off of AZA toxins in shellfish $(0.16 \mu \mathrm{g} / \mathrm{g})$. Red dashed line represents the level of a high volume algal bloom.

toxins in the Q3 of 2013. However, a very different trend was observed for 2014, with AZA toxin levels exceeding the regulatory cut-off throughout $\mathrm{Q} 1$ and $\mathrm{Q} 2$ of the year. Figure 2 displays a similar dataset but from samples acquired off the coast of Co. Galway, Ireland. Even with a geographical difference of only a few hundred kilometres, a very different trend for the occurrences of AZA toxins was observed. In 2013, Q1 experienced levels exceeding the cut-off limit, while Q3 and Q4 displayed levels up to 12-fold greater than the cut-off. In 2014, Q1 experienced AZA levels exceeding the cut-off, while the remainder of the year was largely below the cut-off. This comes despite the very high cell concentrations of Azadinium/Heterocapsa spp. that occurred at this time, with levels exceeding $10^{6}$ cells/L. Such trends may give credence to the growth characteristics observed by Jauffrais et al., [8], in which AZA cell quota was found to be antagonist to growth, that is cells that grew faster had lower intracellular AZA concentrations and vice versa. These data also highlight the significant variation of cell concentration and shellfish toxin levels observed annually.

\section{HABs present a significant monitoring challenge}

HABs present a significant challenge in terms of predicting when and where a bloom may occur and the scale of a bloom. A myriad of factors play a role in influencing the dynamics of bloom growth. Physical factors include temperature [9,10], salinity, current, water level [11], turbulence, shear [12], occurrence of upwelling or downwelling winds [10], light availability [9] and biological factors, such as excystment behaviour [13], tropism and cell-cell interactions [14], among others (see graphical abstract). Human activities such as sewage-dumping and agricultural run-off are also linked closely to the occurrences of HABs. 


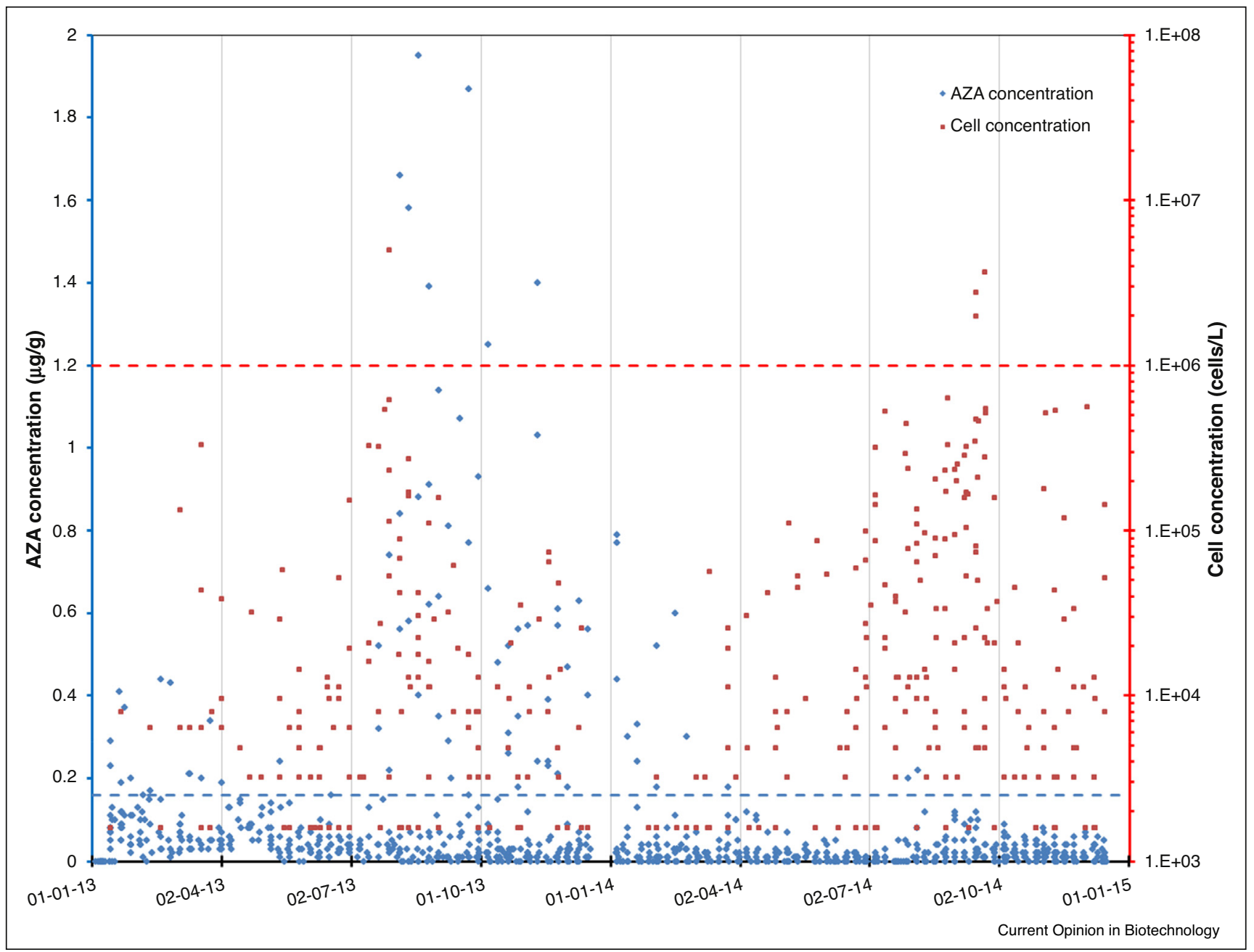

Occurrences of Axadinium/Heterocapsa spp. and AZA toxins (in shellfish) off the Galway coast from 2013 to 2014. Blue dashed line represents the current regulatory cut-off of AZA toxins in shellfish $(0.16 \mu \mathrm{g} / \mathrm{g})$. Red dashed line represents the level of a high volume algal bloom.

Nutrient-loading into fresh and marine water bodies, especially from phosphorus- and nitrogen-containing sources, can lead to proliferation of HABs, leading to eutrophication [15-18]. In addition to effecting HABs and toxin-production, the above-mentioned factors also play a role in shellfish toxicity as a result of toxic algal blooms. However, shellfish toxicity exhibits no or only weak correlation between the individual factors described. It is more likely that shellfish toxicity occurs due to complex interactions between numerous factors [19], which creates a greater level of complexity to accurately predict shellfish toxicity.

An established means to predict the spatial and temporal occurrences of HABs is through the development of predictive models. However, the requirement of up-todate and high resolution sampling data on the water's physical characteristics and the current algal and toxin levels is of paramount importance for predictive models to give a reliable forecast [20-22]. Real-time data on harmful algae and toxins is required for use of bloom forecasts models, and is analogous to the way that weather forecasts require up-to-date meteorological data. Therefore, the currently employed laboratory methods for monitoring algal species and their toxins are not sufficiently rapid to provide up-to-date data required for accurate modelling. However, a promising means to monitor HABs and marine toxins in situ, with a low cost, high sensitivity and rapid turnaround time is in the form of biosensors. Such systems incorporate biorecognition elements with a chemical or physical measurement element to allow for detection and quantification of a target analyte. The theory of biosensors has been discussed extensively in other review articles [23,24]. Additionally, biosensors designed to specifically measure marine toxins have been previously reviewed $[25,26]$. Therefore, the focus of this review will be on recently 
developed biosensors that can detect, quantify and identify harmful algal species (HAS).

\section{Biosensors to detect harmful algal species}

In the previous 5 years, much effort in the area of algal biosensors has been focused on the development of nucleic acid-based methods for identification of HAS. This is due to the excellent sensitivity and specificity of nucleic acid probes to their complementary binding partners, the majority of which target ribosomal RNA (rRNA) or DNA (rDNA). In the authors' literature search, such nucleic-acid based methods have come in the form of those with quantitative polymerase chain reaction (qPCR) at the heart of the assays or those based on multiplexed microarray technology. qPCR has the distinct advantage of exquisite sensitivity, due to the ability of polymerase enzymes to amplify very small quantities of target RNA or DNA. Microarrays, on the other hand, utilise RNA or DNA probes printed or spotted onto a support matrix, with each spot dedicated to the detection of a different algal genus or species. Thus, microarrays have an excellent broad range of detection. In addition to nucleic-acid based methods, some research has focused on the development of antibodies to target distinct protein biomarkers that can be used to identify HAS. In the following section, these recently developed biosensors will be discussed, paying attention to their advantages and disadvantages, and how they will better serve the pressing need to improve HAS-monitoring.

The ALGADEG system, developed by Diercks-Horn et al. [27], is a semi-automated rRNA biosensor. This system was used to detect Alexandium minutum, with the potential to detect 14 different HAS. Sample-analysis took only 2 hours, in which the user need only carry out sample filtration and sample addition to the device. The analysis does not require specialised equipment or advanced user-training. However, the limit of detection of $6250 \mathrm{~A}$. minutum cells may not be sensitive enough to detect low levels of this strain. A similar system was developed by Orozco et al. [28]. This genosensor array can detect the RNA of 13 HAS, with a limit of detection of $10^{5}$ cells in spiked seawater samples. However, this system requires numerous sample-handling steps in terms of acquisition, concentration and subsequent extraction of RNA.

Chen et al. [29] have developed a reverse dot blot hybridisation (RDBH) array that can currently detect five HAS. This system makes use of PCR to detect as few as 10 cells. While the system is currently limited to detection of 5 target species, the nylon membrane array can be expanded to allow for detection of a greater number of target species and the array is easy to fabricate. The array signal can be visualised by naked eye or by specialised equipment, meaning the results are semi-quantitative. Thus, this system is suitable for use as early-warning of impending or on-going blooms, but further analysis would be required to determine definitive cell numbers.

McCoy et al. $\left[30^{\bullet}, 31\right]$ have described a multiplex RNA microarray platform (MIDTAL, currently available commercially from Microbia Environnement) that can detect and quantify numerous Alexandrium species. This system would be suitable for improved lab-based detection and identification of HAS. It is not yet amenable for point-ofneed (PON) monitoring, as it requires a number of sample-preparation steps. This system is further described by Dittami et al. [32]. The microarray contains 140 different probes for detection of various HAS, including numerous toxin-producing algae. A disadvantage of this system is due to variability depending on the extraction efficiency, labelling and quality of RNA in the sample. However, this system shows great promise for the high-throughput species-level identification of HAS. From our literature search, it has become apparent that a potential issue with RNA biosensors may be due to discrepancies between cell numbers determined by rRNA measurement and direct cell counting, which is due to varying amounts of RNA per cell, a factor that is dependent of cell size and growth rate [33]. Thus, this factor would need thorough investigation and correlation to current techniques prior to the deployment of such RNA biosensors.

Gas et al. [34] developed monoclonal antibodies (mAbs) that specifically recognise surface markers of $A$. minutum and that showed low cross-reactivity to other HAS. These mAbs were incorporated into a magnetic lateral flow immunoassay (LFIA) that could measure A. minutum cells in 30 min with a limit of quantification (LOQ) of $10^{5}$ cells/ $\mathrm{L}\left[35^{\circ}\right]$. It also showed good correlation of results obtained by LM but without the subjective userinterpretation.

A notable sensor developed in recent years is the Environmental Sample Processor (ESP). This is among the first in-situ, autonomous systems for the monitoring of HABs and their toxins [36-38]. Recently, it features an in situ sandwich hybridisation assay (SHA) and qPCR for the detection and quantitation of Pseudo-nitsschia RNA and DNA, respectively, to a species level [39 ${ }^{\bullet \bullet}$ ]. The system was capable of detecting Pseudo-nitzschia spp. $\sim 100$ cells/ $\mathrm{L}$ or $\sim 10$ DNA copies/L by SHA and qPCR, respectively. The incorporation of two assay formats also allows for flexibility of detection. The ESP also autonomously carries out sample acquisition, nucleic acid extraction and sample-partitioning for multiple assays. Additional advantages of the ESP include the ability to be deployed at sea for 45 days and to report results wirelessly within hours of acquisition. However, a limitation of the qPCR assay would be the number of potential algal species that could be detected. This would be limited by the number of distinct fluorescent probes that could be used in 
tandem, due to overlap of fluorescent signals. However, the SHA utilises an array format, which has greater potential for scaling up to accommodate the analysis of a greater number of HAS. The ESP was reviewed in greater detail by Ottesen $\left[40^{\circ}\right]$.

With the exception of the ESP system, none of the above mentioned biosensors are quite ready to be deployed at the PON. However, these systems show promise in terms of reducing the cost of sample analysis and reduction of analysis times. The microarray based systems, in particular the MIDTAL system, show great promise to allow for detection of a high number of HAS in-tandem. The main disadvantage of such microarrays is detection sensitivity, however, a number of strategies may be employed to increase such sensitivity $[41,42]$. Other disadvantages, such as sample extraction and handling, may be addressed through the use of automated microfluidics [43].

\section{Conclusion}

In the realm of HAB research and monitoring, the identification of causative species and associated toxins is paramount to understanding bloom dynamics and toxicity and to mitigating their impact. A key strategy for predicting HABs is the development of predictive models, but the reliability of such models requires up-to-date, high resolution data on HABs occurrences. Biosensors present an attractive means to establish such up-to-date, high resolution data, due to their low cost, excellent performance and their ability to be deployed at the PON. This review summarised a number of recently developed biosensors designed to detect and identify HAS. Much focus has been on the development of nucleic acid-based biosensors, such as qPCR and microarray formats. The advantages and disadvantages of these biosensors were discussed. Currently, the technology is not quite at the stage of PON deployment, but with incorporation of new technologies, such as microfluidics and nanomaterials, these biosensors may be deployable in the marine environment within the next five years. Once there, such systems should help to improve HAB monitoring, which will allow for improved prediction and mitigation of their harmful effects.

\section{Acknowledgements}

We acknowledge support from Science Foundation Ireland [grant number 14/1A/2646] and the Irish Research Council. The authors have no other relevant affiliations or financial involvement with any organization or entity with a financial interest in or financial conflict with the subject matter or materials discussed in the manuscript apart from those disclosed.

\section{References and recommended reading}

Papers of particular interest, published within the period of review, have been highlighted as:

- of special interest

•• of outstanding interest
1. Sanseverino I, Conduto ADS, Pozzoli L, Dobricic S, Lettieri T: Algal

- bloom and its economic impact. JRC Tech. Rep. Eur. Comm. $2016 \mathrm{http}: / / \mathrm{dx}$.doi.org/10.2788/660478. EUR $27905 \mathrm{EN}$.

This article describes in great detail the background behind harmful algal blooms and marine toxins. It gives a comprehensive summary of the economic impacts of algal blooms from the perspectives of human health impacts, commercial fishery impacts, tourism/recreation impacts and monitoring and management impacts.

2. Smetacek V: A watery arms race. Nature 2001, 411:745.

3. McCarthy M, van Pelt FNAM, Bane V, O'Halloran J, Furey A: Application of passive (SPATT) and active sampling methods in the profiling and monitoring of marine biotoxins. Toxicon 2014, 89:77-86.

4. Silke J, Duffy C, Clarke D: HABs inshore shellfish monitoring data. Retrieved December 21, 2016, from http://data.marine.ie/ Dataset/Details/20935.

5. Silke J, Salas R, Clarke D: HABs inshore phytoplankton monitoring data. Retrieved December 21, 2016, from http://data. marine.ie/Dataset/Details/20944.

6. European Commission. Commission regulation (EU) No 15/2011 OJ L6/3.

7. European Commission. Commission regulation (EU) No 2074/ 2005. OJ L338/27.

8. Jauffrais $\mathrm{T}$, Séchet $\mathrm{V}$, Herrenknecht $\mathrm{C}$, Truquet $\mathrm{P}$, Véronique $\mathrm{S}$, Tillmann U, Hess P: Effect of environmental and nutritional factors on growth and azaspiracid production of the dinoflagellate Azadinium spinosum. Harmful Algae 2013, 27:138-148.

9. Horecka HM, Thomas AC, Weatherbee RA: Environmental links to interannual variability in shellfish toxicity in Cobscook Bay and eastern Maine, a strongly tidally mixed coastal region. Deep Sea Res. Part II 2014, 103:318-328.

10. Nair A, Thomas AC, Borsuk ME: Interannual variability in the timing of New England shellfish toxicity and relationships to environmental forcing. Sci. Total Environ. 2013, 447:255-266.

11. Cusack C, Dabrowski T, Lyons K, Berry A, Westbrook G, Salas R, Duffy C, Nolan G, Silke J: Harmful algal bloom forecast system for SW Ireland. Part II: are operational oceanographic models useful in a HAB warning system. Harmful Algae 2016, 53:86-101.

12. Farrell H, Gentien P, Fernand L, Lunven M, Reguera B, GonzálezGil S, Raine R: Scales characterising a high density thin layer of Dinophysis acuta Ehrenberg and its transport within a coastal jet. Harmful Algae 2012, 15:36-46.

13. Ní Rathaille A, Raine R: Seasonality in the excystment of Alexandrium minutum and Alexandrium tamarense in Irish coastal waters. Harmful Algae 2011, 10:629-635.

14. Jonsson PR, Pavia H, Toth G: Formation of harmful algal blooms cannot be explained by allelopathic interactions. Proc. Natl. Acad. Sci. 2009, 106:11177-11182.

15. Zhou Z, Yu R, Zhou M: Resolving the complex relationship between harmful algal blooms and environmental factors in the coastal waters adjacent to the Changjiang River estuary. Harmful Algae 2017, 62:60-72.

16. Ulloa MJ, Álvarez-Torres P, Horak-Romo KP, Ortega-Izaguirre R Harmful algal blooms and eutrophication along the Mexican coast of the Gulf of Mexico large marine ecosystem. Environ. Dev. 2017. in press.

17. Watson SB, Miller C, Arhonditsis G, Boyer GL, Carmichael W, Charlton MN, Confesor R, Depew DC, Höök TO, Ludsin SA et al: The re-eutrophication of Lake Erie: harmful algal blooms and hypoxia. Harmful Algae 2016, 56:44-66.

18. Mostofa KMG, Liu C, Vione D, Gao K, Ogawa H: Sources, factors, mechanisms and possible solutions to pollutants in marine ecosystems. Environ. Pollut. 2013, 182:461-478.

19. Turner AD, Stubbs B, Coates L, Dhanji-Rapkova M, Hatfield RG Lewis AM, Rowland-Pilgrim S, O'Neil A, Stubbs P, Ross S et al.: Variability of paralytic shellfish toxin occurrence and profiles in bivalve molluscs from Great Britain from official control monitoring as determined by pre-column oxidation liquid 
chromatography and implications for applying immunochemical tests. Harmful Algae 2014, 31:87-99.

20. Anderson DM, Cembella AD, Hallegraeff GM: Progress in understanding harmful algal blooms: paradigm shifts and new technologies for research, monitoring, and management Ann. Rev. Mar. Sci. 2012, 4:143-176.

21. Dabrowski T, Lyons K, Nolan G, Berry A, Cusack C, Silke J: Harmful algal bloom forecast system for SW Ireland. Part I: description and validation of an operational forecasting model. Harmful Algae 2016, 53:64-76.

22. Dale B, Murphy M: A retrospective appraisal of the importance of high-resolution sampling for harmful algal blooms: lessons from long-term phytoplankton monitoring at Sherkin Island, S. W. Ireland. Harmful Algae 2014, 40:23-33.

23. Hassan SHA, Van Ginkel SW, Hussein MAM, Abskharon R, Oh S: Toxicity assessment using different bioassays and microbial biosensors. Environ. Int. 2016, 92-93:106-118.

24. McPartlin DA, O'Kennedy RJ: Point-of-care diagnostics, a major opportunity for change in traditional diagnostic approaches: potential and limitations. Expert Rev. Mol. Diagn. 2014, 14:979-998

25. McPartlin DA, Lochhead MJ, Connell LB, Doucette GJ, O'Kennedy RJ: Use of biosensors for the detection of marine toxins. Essays Biochem. 2016, 60:49-58.

26. Moran KLM, Fitzgerald J, McPartlin DA, Loftus JH, O'Kennedy R: Chapter 4-biosensor-based technologies for the detection of pathogens and toxins. Comprehensive Analytical Chemistry. Elsevier; 2016:: 93-120

27. Diercks-Horn S, Metfies K, Jäckel S, Medlin LK: The ALGADEC device: a semi-automated rRNA biosensor for the detection of toxic algae. Harmful Algae 2011, 10:395-401.

28. Orozco J, Villa E, Manes C, Medlin LK, Guillebault D: Electrochemical RNA genosensors for toxic algal species: enhancing selectivity and sensitivity. Talanta 2016, 161:560 566.

29. Chen GF, Zhang CY, Wang YY, Chen W: Application of reverse dot blot hybridization to simultaneous detection and identification of harmful algae. Environ. Sci. Pollut. Res. 2015, 22:10516-10528.

30. McCoy GR, Touzet N, Fleming GTA, Raine R: Evolution of the

- MIDTAL microarray: the adaption and testing of oligonucleotide $18 S$ and $28 S$ rDNA probes and evaluation of subsequent microarray generations with Prymnesium spp. cultures and field samples. Environ. Sci. Pollut. Res. 2015 , 22:9704-9716.

The MIDTAL system described in this paper is a notable system that allows for large-scale analysis of many harmful algal species on a single array. Such large-scale analysis will be critical in future research in this field, especially in the area of algal blood modelling.

31. McCoy GR, McNamee S, Campbell K, Elliott CT, Fleming GTA, Raine R: Monitoring a toxic bloom of Alexandrium minutum using novel microarray and multiplex surface plasmon resonance biosensor technology. Harmful Algae 2014, 32 40-48.

32. Dittami SM, Pazos Y, Laspra M, Medlin LK: Microarray testing for the presence of toxic algae monitoring programme in Galicia (NW Spain). Environ. Sci. Pollut. Res. 2013, 20:6778-6793.

33. Edvardsen B, Dittami SM, Groben R, Brubak S, Escalera L, RodrÃguez F, Reguera B, Chen J, Medlin LK: Molecular probes and microarrays for the detection of toxic algae in the genera Dinophysis and Phalacroma (Dinophyta). Environ. Sci. Pollut. Res. 2013, 20:6733-6750.

34. Gas F, Pinto L, Baus B, Gaufres L, Crassous M, Compere C, Quéméneur E: Monoclonal antibody against the surface of Alexandrium minutum used in a whole-cell ELISA. Harmful Algae 2009, 8:538-545

35. Gas F, Baus B, Queré J, Chapelle A, Dreanno C: Rapid detection

- $\quad$ and quantification of the marine toxic algae, Alexandrium minutum, using a super-paramagnetic immunochromatographic strip test. Talanta 2016, 147:581-589. This technology was the only example of immunoassay-based detection of harmful algal species encountered in the authors' literature survey. This system uses high specificity antibodies to target algal biomarkers and is coupled to an easy-to-use test strip that is amenable to point-of-need use.

36. Greenfield DI, Marin R, Jensen S, Massion E, Roman B, Feldman J, Scholin CA: Application of environmental sample processor (ESP) methodology for quantifying Pseudo-nitzschia australis using ribosomal RNA-targeted probes in sandwich and fluorescent in situ hybridization formats. Limnol. Oceanogr. Methods 2006, 4:426-435.

37. Greenfield DI, Marin R, Doucette GJ, Mikulski C, Jones K, Jensen S, Roman B, Alvarado N, Feldman J, Scholin C: Field applications of the second-generation Environmental Sample Processor (ESP) for remote detection of harmful algae: 2006-2007. Limnol. Oceanogr. Methods 2008, 6:667-679.

38. Scholin C, Doucette G, Jensen S, Roman B, Pargett D, Roman Mri III, Preston C, Jones W, Feldman J, Everlove C et al.: Remote detection of marine microbes, small invertebrates, harmful algae, and biotoxins using the environmental sample processor (ESP). Oceanography 2009.

39. Yamahara KM, Demir-Hilton E, Preston CM, Marin R, Pargett D,

- Roman B, Jensen S, Birch JM, Boehm AB, Scholin CA: Simultaneous monitoring of faecal indicators and harmful algae using an in-situ autonomous sensor. Lett. Appl. Microbiol. 2015, 61:130-138.

The Environmental Sample Processor described in this article represents cutting-edge technology for the monitoring of faecal indications and harmful algal species. This system allows for autonomous in-situ monitoring and is deployable in the ocean for over 45 days.

40. Ottesen EA: Probing the living ocean with ecogenomic - $\quad$ sensors. Curr. Opin. Microbiol. 2016, 31:132-139.

This review comprehensively describes recently developed sensors that allow for continuous monitoring or collection of marine biological samples.

41. Gao W, Wang W, Yao S, Wu S, Zhang H, Zhang J, Jing F, Mao H, Jin Q, Cong Het al.: Highly sensitive detection of multiple tumor markers for lung cancer using gold nanoparticle probes and microarrays. Anal. Chim. Acta 2016, 958:77-84.

42. Mavrogiannopoulou E, Petrou PS, Koukouvinos G, Yannoukakos D, Siafaka-Kapadai A, Fornal K, Awsiuk K, Budkowski A, Kakabakos SE: Improved DNA microarray detection sensitivity through immobilization of preformed in solution streptavidin/biotinylated oligonucleotide conjugates Colloids Surf. B: Biointerfaces 2015, 128:464-472.

43. Jayamohan $\mathrm{H}$, Romanov V, Li H, Son J, Samuel R, Nelson J, Gale BK: Chapter 11-advances in microfluidics and lab-on-achip technologies. In Molecular Diagnostics (Third Edition). Edited by Patrinos GP. Academic Press; 2017:197-217. 